\title{
Deletion of the TNFAIP3/A20 gene detected by FICTION analysis in classical Hodgkin lymphoma
}

\author{
Junko Nomoto ${ }^{1,2}$, Nobuhiro Hiramoto ${ }^{1}$, Motohiro Kato ${ }^{3}$, Masashi Sanada ${ }^{3}$, Akiko Miyagi Maeshima ${ }^{4}$, \\ Hirokazu Taniguchi ${ }^{4}$, Fumie Hosoda ${ }^{5}$, Yoshitaka Asakura ${ }^{1}$, Wataru Munakata', Naohiro Sekiguchi ${ }^{1}$, Dai Maruyama ${ }^{1}$, \\ Takashi Watanabe ${ }^{1}$, Hitoshi Nakagama ${ }^{6}$, Kengo Takeuchi ${ }^{7}$, Kensei Tobinai ${ }^{1}$, Seishi Ogawa ${ }^{3}$ and Yukio Kobayashi ${ }^{1 *}$
}

\begin{abstract}
Background: The TNFAIP3 gene, which encodes a ubiquitin-modifying enzyme (A20) involved in the negative regulation of NF-KB signaling, is frequently inactivated by gene deletions/mutations in a variety of B-cell malignancies. However, the detection of this in primary Hodgkin lymphoma $(\mathrm{HL})$ specimens is hampered by the scarcity of Hodgkin Reed-Sternberg (HR-S) cells even after enrichment by micro-dissection.

Methods: We used anti-CD30 immunofluorescence with fluorescence in-situ hybridization (FISH) to evaluate the relative number of TNFAIP3/CEP6 double-positive signals in CD30-positive cells.

Results: From a total of 47 primary classical Hodgkin lymphoma ( $\mathrm{CHL}$ ) specimens, 44 were evaluable. We found that the relative numbers of TNFAIP3/CD30 cells were distributed among three groups, corresponding to those having homozygous (11\%), heterozygous (32\%), and no (57\%) deletions in TNFAIP3. This shows that TNFAIP3 deletions could be sensitively detected using our chosen methods.

Conclusions: Comparing the results with mutation analysis, TNFAIP3 inactivation was shown to have escaped detection in many samples with homozygous deletions. This suggests that TNFAIP3 inactivation in primary $\mathrm{CHL}$ specimens might be more frequent than previously reported.
\end{abstract}

Keywords: FICTION analysis, Hodgkin lymphoma, TNFAIP3 gene, Homozygous deletion

\section{Background}

The TNFAIP3/A20 gene encodes a ubiquitin-modifying enzyme involved in the termination of NF- $\mathrm{KB}$ responses, so is a negative regulator of NF- $\mathrm{KB}$ signaling [1,2]. TNFAIP3 is located on chromosome $6 \mathrm{q} 23$, and deletion of one allele has been detected in Hodgkin lymphoma (HL) and other B-cell malignancies [3-9].

We previously showed that TNFAIP3 is a common genetic target in B-cell lymphomas, following an analysis of 265 samples obtained from various B-cell lymphomas using either comparative genomic hybridization (CGH) or TNFAIP3 mutation analysis. We observed TNFAIP3 mutations and/or deletions in 31 cases [3]. This previous work also included samples from 24 primary classic HL (cHL) cases, and we performed mutation analysis of micro-dissected CD30-positive Hodgkin Reed-Sternberg

\footnotetext{
* Correspondence: ykkobaya@ncc.go.jp

'Hematology Division, National Cancer Center Hospital, Tokyo, Japan Full list of author information is available at the end of the article
}

(HR-S) cells. This revealed one intronic and four missense mutations, indicating the existence of cHL heterogeneity. However, it is conceivable that we did not detect homozygous deletions, which have been shown in other B-cell lymphoma subtypes and HL cell lines, and that we underestimated the frequency of involvement of TNFAIP3 in primary cHL cases.

In order to accurately evaluate the frequency of involvement of TNFAIP3 in cHL, we performed Fzluorescence Immunophenotyping and interphase Cytogenetics as a Tool for the Investigation Of Neoplasm (FICTION) [10] to examine TNFAIP3 deletions in cHL. A total of 47 CHL cases were examined for the presence or absence of TNFAIP3 deletions, including 22 of 24 cases with sequence data previously reported.

\section{Methods}

\section{Samples}

The study consisted of $47 \mathrm{cHL}$ biopsy specimens, including 30 from our previous cohort archived in the National 
Cancer Center (NCC) Hospital between 1997 and 2007, and 17 obtained from The Cancer Institute Hospital of the Japanese Foundation For Cancer Research. This research was carried out in compliance with the Helsinki Declaration, and was approved by the Institutional Review Board at the NCC (20-010).

Twenty-two of the 47 cases had been examined previously by sequence analysis, and four found to have missense mutations. In addition, we examined the sequence of six cases in the present study. Specimens were fixed in formalin or methanol and embedded in paraffin, then cut into thin sections and laid on a glass slide. One section of each specimen was subjected to FICTION analysis and the other to sequence analysis.

\section{FICTION analysis}

Approximately 4- $\mu$ m-thick sections were immunostained with an anti-CD30 antibody to identify HR-S cells. The CD30 antibody (BerH2) (Dako, Glostrup, Denmark) was diluted 100 -fold and incubated overnight at $4^{\circ} \mathrm{C}$. The fluorescence labeled antibodies Alexafluor 647 Rabbit Anti-mouse IgG, Alexafluor 647 Goat Anti-rabbit IgG and Alexafluor 647 Donkey Anti-goat IgG, were used as the secondary, tertiary, and quaternary antibodies, respectively (Molecular Probes, Life Technologies Corporation, Foster City, CA). Each of these antibodies was diluted 1000-fold and incubated for $30 \mathrm{~min}$ at room temperature (RT).

A BAC clone library was screened to identify a clone suitable for the fluorescence in-situ hybridization (FISH) analysis of TNFAIP3. Clone RP11-783B20 (TNFAIP3 locus, 6q23) was selected based on the best signal/noise ratio upon hybridization to the normal karyotype (Abbot Laboratories, Abbot, IL). RP11-783B20 was labeled with spectrum orange by nick translation (Abbot Laboratories) according to the manufacturer's instructions. The CEP6 Spectrum Green Probe (Abbot Laboratories) was used to detect the centromere of chromosome 6 (6p11.1-q11) as a reference. Double-color FISH was performed using the Histology FISH Accessory kit (Dako). The hybridization mixture consisted of $2 \mu \mathrm{l}$ of the TNFAIP3 probe, $2 \mu \mathrm{l}$ of the 1/20-diluted CEP 6 probe, $1 \mu \mathrm{l}$ of Cot1-DNA, and $5 \mu \mathrm{l}$ of $20 \%$ dextran sulfate $/ 4 \times \mathrm{SSC}$. After denaturation at $76^{\circ} \mathrm{C}$ for $6 \mathrm{~min}$, the solutions were laid onto a glass slide and incubated overnight at $37^{\circ} \mathrm{C}$ for hybridization according to the manufacturer's instructions. Nuclear staining was performed with DAPI. We visualized the sections under a four-color fluorescence microscope, BIOREVO (Keyence Corporation, Osaka, Japan).

\section{Statistical analysis}

As the diameter of HR-S cells is several-fold greater than the $4 \mu \mathrm{m}$ thickness of the FISH sections, the TNFAIP3/ CEP6 signal ratio was calculated to evaluate the TNFAIP3 status in CD30-positive cells. The signal ratio was also calculated in the surrounding normal CD30negative cells, which were used as a control. We counted the signal ratio for 30 CD30-positive cells and 50 CD30negative cells. Only CD30-positive cells of large morphology were regarded as HL cells.

The cutoff level to estimate gene deletion(s) was determined by calculating the ratio of the TNFAIP3/CEP6 signal in the subject cells to that in the normal control cells in samples showing obvious deletions from sequence analysis. $P$-values $<0.05$ were considered statistically significant.

\section{Results}

In total, specimens from 47 patients were analyzed (Table 1). The predominant type of cHL was nodular sclerosis (NS, $n=28)$, followed by mixed cellularity $(n=14)$, lymphocyte-depletion (LD, $\mathrm{n}=2$ ), and lymphocyte-rich $(\mathrm{LR}, \mathrm{n}=3)$. Of the 47 patients, 19 were male and 28 were female. Disease stages I, II, III and IV were evident in eight, 24, 10 and five cases, respectively. B symptoms were present in 12 cases and absent in the remaining 35 cases. In all, 15 cases tested positive for EBV and the remaining 32 showed a negative result.

The signals were successfully detected in all cases (Figure 1A-D). The mean numbers of TNFAIP3 signals and CEP6 signals per CD30-negative cell were almost the same in most cases, except for cases \#40, 42 and 45 , where the number of TNFAIP3 signals was markedly lower than that of CEP6 signals, with ratios of $0.86,0.89$ and 0.84 , respectively. These cases were excluded from further analysis as the number of available slides was limited and the analysis could not be repeated more than twice. In all remaining cases, the TNFAIP3/CEP6 signal ratio in CD30-negative cells was approximately 1.0 .

The mean number of CEP6 signals in CD30-positive cells was $1.2 \pm 0.3$, which was less than that of CD30negative cells $(1.5 \pm 0.1)$. In addition, the mean number of TNFAIP3 signals per CD30-positive cell was less than that of CEP6; the mean number of TNFAIP3: CEP6 signals per CD30-positive cell was 0.60 , significantly lower than that in control CD30-negative cells $(p<0.001)$. The relative numbers of signals determined by FICTION analysis in the 47 cases are shown in Table 2.

The TNFAIP3/CEP6 signal ratio in CD30-positive cells was divided by that in CD30-negative cells to give the relative TNFAIP3/CEP6 signal ratio; further analysis was then performed to determine whether TNFAIP3 deletions existed in CD30-positive cells. The relative TNFAIP3/CEP6 signal ratio was distributed into three peaks. Construction of a histogram based on 0.05 increments revealed no cases with relative ratios of $0.25-0.30$ or those of $0.55-0.60$, which separated the three distribution peaks. We contended that 
Table 1 Patient characteristics

\begin{tabular}{|c|c|c|c|c|c|c|}
\hline Case \# & Diagnosis & Age (years) & Gender & Stage & B symptom & EBER-1 \\
\hline 1 & NS & 28 & $\mathrm{~F}$ & $\|$ & - & - \\
\hline 2 & NS & 44 & $\mathrm{~F}$ & $\|$ & - & + \\
\hline 3 & NS & 30 & M & I & - & - \\
\hline 4 & NS & 27 & $\mathrm{~F}$ & $\|$ & - & - \\
\hline 5 & NS & 18 & $\mathrm{~F}$ & $\|$ & - & - \\
\hline 6 & NS & 27 & M & $\|$ & + & - \\
\hline 7 & NS & 22 & M & IV & - & - \\
\hline 8 & NS & 57 & M & III & - & - \\
\hline 9 & NS & 48 & M & III & & - \\
\hline 10 & $M C$ & 29 & M & IV & - & - \\
\hline 11 & NS & 34 & M & $\|$ & - & - \\
\hline 12 & NS & 22 & $\mathrm{~F}$ & $\|$ & - & - \\
\hline 13 & NS & 14 & $\mathrm{~F}$ & I & - & - \\
\hline 14 & $M C$ & 53 & M & I & - & - \\
\hline 15 & $M C$ & 59 & M & I & - & + \\
\hline 16 & $M C$ & 42 & M & III & + & - \\
\hline 17 & $M C$ & 50 & M & $\|$ & - & - \\
\hline 18 & $M C$ & 29 & $\mathrm{~F}$ & $\|$ & + & + \\
\hline 19 & $M C$ & 50 & M & I & - & + \\
\hline 20 & NS & 39 & $\mathrm{~F}$ & IV & - & - \\
\hline 21 & NS & 22 & $\mathrm{~F}$ & $\|$ & + & - \\
\hline 22 & $M C$ & 55 & $\mathrm{~F}$ & I & - & + \\
\hline 23 & LD & 59 & $F$ & I & - & - \\
\hline 24 & NS & 32 & $\mathrm{~F}$ & $\|$ & + & - \\
\hline 25 & NS & 16 & $M$ & III & - & - \\
\hline 26 & NS & 24 & $\mathrm{~F}$ & III & - & - \\
\hline 27 & NS & 20 & $M$ & $\|$ & - & - \\
\hline 28 & $M C$ & 67 & $\mathrm{~F}$ & IV & + & + \\
\hline 29 & NS & 26 & $\mathrm{~F}$ & $\|$ & - & - \\
\hline 30 & $M C$ & 73 & $\mathrm{~F}$ & IV & - & + \\
\hline 31 & $M C$ & 74 & $\mathrm{~F}$ & $\|$ & - & - \\
\hline 32 & $L R$ & 81 & $\mathrm{~F}$ & $\|$ & - & - \\
\hline 33 & $M C$ & 75 & $F$ & III & + & + \\
\hline 34 & $M C$ & 33 & $\mathrm{~F}$ & III & + & - \\
\hline 35 & $M C$ & 62 & $\mathrm{~F}$ & III & - & + \\
\hline 36 & $M C$ & 53 & $M$ & $\|$ & - & + \\
\hline 37 & $L R$ & 72 & $M$ & $\|$ & - & + \\
\hline 38 & NS & 16 & $\mathrm{~F}$ & $\|$ & - & - \\
\hline 39 & NS & 36 & $\mathrm{~F}$ & $\|$ & + & - \\
\hline 40 & NS & 16 & $\mathrm{~F}$ & $\|$ & - & - \\
\hline 41 & $L R$ & 48 & $M$ & III & + & + \\
\hline 42 & LD & 67 & $M$ & I & - & + \\
\hline 43 & NS & 27 & $\mathrm{~F}$ & $\|$ & - & - \\
\hline 44 & NS & 43 & $\mathrm{~F}$ & $\|$ & - & - \\
\hline
\end{tabular}


Table 1 Patient characteristics (Continued)

\begin{tabular}{|c|c|c|c|c|c|c|}
\hline 45 & NS & 64 & $M$ & $\|$ & + & - \\
\hline 46 & NS & 66 & $\mathrm{~F}$ & III & - & + \\
\hline 47 & NS & 24 & $\mathrm{~F}$ & $\|$ & - & + \\
\hline
\end{tabular}

NS, Nodular sclerosis $\mathrm{CHL} ; M C$, Mixed cellularity $\mathrm{cHL} ; L D$, Lymphocyte-depleted $\mathrm{cHL} ; L R$, lymphocyte-rich $\mathrm{cHL}$.

each of these peaks corresponded to the TNFAIP3 deletion status. The first peak, corresponding to the lowest relative ratios, was considered to represent cases with homozygous deletions; the second peak, corresponding to intermediate ratios, represented cases with heterozygous deletions; and the third peak, corresponding to the highest relative ratios, represented cases with no deletions. Two cutoff levels were thus determined (0.25 and 0.55), distinguishing between cases with homozygous deletions and heterozygous deletions, and between cases with heterozygous and no deletions, respectively.

Using these two cutoff levels, we determined that five of the 44 cases had homozygous deletions and 14 cases had heterozygous deletions. The relative TNFAIP3/CEP6 signal ratios in the former cases $(\# 6,12,21,26$, and 41) were $0.13,0.21,0.22,0.14$, and 0.21 , respectively, suggestive of almost complete loss of TNFAIP3. In two of these cases (\#6, and \#41), sequence analysis had previously been performed [3], and only wild type sequence had been shown. Fourteen cases were assumed to have heterozygous deletions, of which nine had previously undergone sequence analysis revealing no mutations.
The remaining 25 cases were assumed to have no deletions, of which 14 had previous sequence data showing three cases (\#3, \#38, and \#46) with gene mutations. The sequencing analysis revealed no residual wild-type TNFAIP3. In these cases, the relative TNFAIP3/CEP6 signal ratio was $0.72,0.69$, and 0.70 , respectively.

We next carried out statistical analysis of the relationship between TNFAIP3 deletions as detected by FICTION analysis and clinical data. The frequency of TNFAIP3 deletions was higher in cases with B symptoms, although the difference was not statistically significant $(p=0.11)$ (Table 3$)$. There were no significant differences related to the patient gender, cHL type, or the disease stage. Cases with mutated TNFAIP3 were then combined with those with deletions, again revealing no statistically significant correlations with clinic pathological characteristics (data not shown).

The frequency of deletions was not significantly different between cases with and without evidence of EBV infection. However, all NS type cases with homozygous TNFAIP3 deletions were found to be negative for EBV; among the remaining 40 cases, 13 tested positive for EBV.
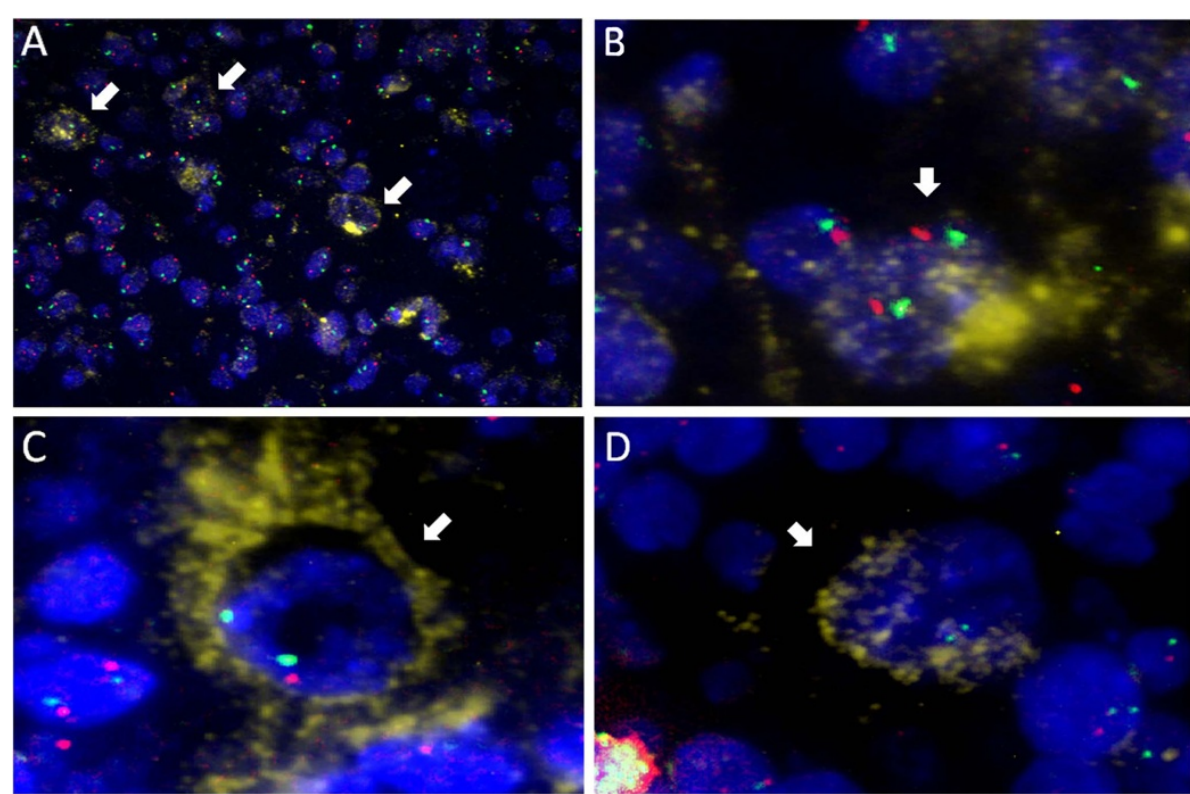

Figure 1 Results of FICTION analysis. FICTION assay combining CD30-expressing cells (yellow) and FISH probes for A20 (red) and chromosome 6 centromere (green). White arrows indicate CD30-positive cells. (A) Low-power field (×300). (B) Normal cells. (C) Heterozygous deletion. (D) Homozygous deletion $(\times 1,000)$. 
Table 2 FICTION analysis

\begin{tabular}{|c|c|c|c|c|c|}
\hline Case \# & Mutation & $\begin{array}{l}\text { Control } \\
\text { CD30-) }\end{array}$ & $\begin{array}{c}\text { HR-S } \\
\text { (CD30+) }\end{array}$ & $\begin{array}{c}\text { HR-S/ } \\
\text { Control }\end{array}$ & $\begin{array}{c}\text { Predicted } \\
\text { allele* }^{*}\end{array}$ \\
\hline 1 & W & 1.02 & 0.90 & 0.88 & 2 \\
\hline 2 & W & 0.98 & 0.63 & 0.64 & 2 \\
\hline 3 & $\begin{array}{c}1487 C>A \\
(T 474 N)\end{array}$ & 0.99 & 0.71 & 0.72 & 2 \\
\hline 4 & W & 1.11 & 0.80 & 0.72 & 2 \\
\hline 5 & W & 1.11 & 0.54 & 0.49 & 1 \\
\hline 6 & W & 1.06 & 0.14 & 0.13 & 0 \\
\hline 7 & W & 0.94 & 0.65 & 0.69 & 2 \\
\hline 8 & W & 0.96 & 0.45 & 0.47 & 1 \\
\hline 9 & W & 1.01 & 0.64 & 0.63 & 2 \\
\hline 10 & W & 0.97 & 0.77 & 0.79 & 2 \\
\hline 11 & W & 1.02 & 0.81 & 0.79 & 2 \\
\hline 12 & ND & 1.03 & 0.22 & 0.21 & 0 \\
\hline 13 & ND & 0.99 & 0.93 & 0.94 & 2 \\
\hline 14 & ND & 1.12 & 0.78 & 0.70 & 2 \\
\hline 15 & ND & 1.04 & 0.83 & 0.80 & 2 \\
\hline 16 & ND & 1.05 & 0.42 & 0.40 & 1 \\
\hline 17 & ND & 1.19 & 1.07 & 0.90 & 2 \\
\hline 18 & ND & 1.00 & 0.67 & 0.67 & 2 \\
\hline 19 & ND & 1.17 & 0.50 & 0.43 & 1 \\
\hline 20 & ND & 0.99 & 0.90 & 0.91 & 2 \\
\hline 21 & ND & 0.95 & 0.21 & 0.22 & 0 \\
\hline 22 & ND & 0.97 & 0.68 & 0.70 & 2 \\
\hline 23 & ND & 0.93 & 0.71 & 0.76 & 2 \\
\hline 24 & ND & 0.99 & 0.70 & 0.71 & 2 \\
\hline 25 & ND & 1.00 & 0.82 & 0.82 & 2 \\
\hline 26 & ND & 1.00 & 0.14 & 0.14 & 0 \\
\hline 27 & ND & 1.02 & 0.32 & 0.31 & 1 \\
\hline 28 & ND & 0.99 & 0.50 & 0.51 & 1 \\
\hline 29 & ND & 0.99 & 0.41 & 0.41 & 1 \\
\hline 30 & ND & 0.97 & 0.76 & 0.78 & 2 \\
\hline 31 & W & 1.03 & 0.45 & 0.44 & 1 \\
\hline 32 & W & 1.01 & 0.88 & 0.86 & 2 \\
\hline 33 & W & 0.97 & 0.52 & 0.53 & 1 \\
\hline 34 & W & 0.99 & 0.52 & 0.52 & 1 \\
\hline 35 & W & 1.00 & 0.93 & 0.93 & 2 \\
\hline 36 & W & 0.90 & 0.63 & 0.71 & 2 \\
\hline 37 & W & 0.98 & 0.43 & 0.44 & 1 \\
\hline 38 & $\begin{array}{c}1777 \mathrm{G}>\mathrm{A} \\
(\mathrm{V} 571 \mathrm{I})\end{array}$ & 1.04 & 0.72 & 0.69 & 2 \\
\hline 39 & W & 1.06 & 1.00 & 0.94 & 2 \\
\hline 40 & $\begin{array}{c}1156 A>G \\
(R 364 G)\end{array}$ & 0.86 & 0.15 & 0.17 & ND \\
\hline 41 & W & 0.91 & 0.19 & 0.21 & 0 \\
\hline 42 & W & 0.89 & 0.31 & 0.35 & ND \\
\hline
\end{tabular}

Table 2 FICTION analysis (Continued)

\begin{tabular}{cccccc}
\hline 43 & W & 1.00 & 0.36 & 0.36 & 1 \\
44 & W & 1.01 & 0.52 & 0.51 & 1 \\
45 & W & 0.84 & 0.68 & 0.81 & ND \\
46 & $569 \mathrm{G}>\mathrm{A}$ & 0.99 & 0.69 & 0.70 & 2 \\
& (STOP) & & & & \\
47 & W & 1.00 & 0.45 & 0.45 & 1 \\
\hline & $3 / 25(12 \%)$ & Mean 1.01 & Mean 0.61 & Mean 0.60 & \\
\hline
\end{tabular}

* 0: homozygous, 5 cases; 1: heterozygous, 14 cases; 2: non deleted, 25 cases. W, wild type; ND, not determined.

Cases \#1-5 and \#31-47 had been sequenced and reported elsewhere. Cases \#6-11 were sequenced in this study. Cases \#12-30 were not sequenced because of limited or poor quality DNA.

\section{Discussion}

FICTION analysis is useful to detect gain-of-function gene deletions in certain cells [4], and was used in the present study to evaluate the frequency of TNFAIP3 deletions in cHL. In FISH analysis, use of thinner sections enables improved probe penetration and better signal visualization. However, as the average HR-S cell is $30-50 \mu \mathrm{m}$ in diameter, this far exceeds the maximum FISH section thickness of $4 \mu \mathrm{m}$, so evaluation of signal number is difficult. We conducted the analysis in a large number of cells, calculated the TNFAIP3/CEP6 signal ratio and determined the cutoff level, which contributed to the determination of allele frequency at the TNFAIP3 locus in cHL cases.

Of the 44 evaluable cases, 19 had deletions, which is consistent with the frequency reported in a previous deletion study (9/21) [7], confirming that TNFAIP3 is frequently lost in malignant cells in cHL. Five cases had homozygous deletions and two of these had a normal sequence, possibly because of contamination from surrounding cells which cannot be avoided during microdissection. Thus, homozygous deletions might be missed in sequence analysis of HR$\mathrm{S}$ cells. For this reason, our previous study only included

Table 3 Univariate analysis

\begin{tabular}{cccc}
\hline Clinical characteristics & $\begin{array}{c}\text { Number of } \\
\text { alleles: } \mathbf{2}\end{array}$ & $\begin{array}{c}\text { Number of } \\
\text { alleles: } \mathbf{0 , 1}\end{array}$ & $\boldsymbol{p}$-value \\
\hline NS & 14 & 12 & 0.63 \\
Others & 11 & 8 & \\
\hline I - I & 17 & 12 & 0.74 \\
III - IV & 8 & 7 & \\
\hline B + & 4 & 7 & 0.11 \\
B - & 21 & 12 & \\
\hline EBV + & 8 & 6 & 0.98 \\
EBV - & 17 & 13 & \\
\hline M & 10 & 7 & 0.83 \\
F & 15 & 12 & \\
\hline
\end{tabular}

NS, Nodular sclerosis $\mathrm{CHL} ; \mathrm{M}$, male; $\mathrm{F}$, female. 
cases in which the sequence analysis was successful. Cases with homozygous deletions might also have been excluded because of unsuccessful PCR amplification, irrespective of DNA quality. If these cases had been included, the frequency of TNFAIP3 homozygous deletions might be much higher than previously thought.

The allele status of case \#40 could not be determined because of the limited sample number; however, this case had a very low TNFAIP3/CEP6 signal ratio. A previous sequence analysis of the same case revealed both mutated and wild-type alleles. If it is assumed that the HR-S cells were diploid, the results could be sorted into homozygous, heterozygous, and no deletions. However, karyotype analysis previously demonstrated the cells to be triploid or tetraploid in some cases [11]. Therefore, it is possible that the mutated allele co-exists with two or three wild-type alleles in triploidy or tetraploidy, respectively. Alternatively, this could be explained by tumor cell heterogeneity in which HR-S is a mixture of cells with a mutated gene and cells with deleted genes.

Of the 14 cases identified to have heterozygous deletions, sequence analysis data were available for nine but no mutations were detected in any of these cases. This could be a result of the gene repression caused by promoter methylation, which was shown for MALT lymphoma by Chanudet et al. [7]. In cases of MALT and other lymphomas, TNFAIP3 has been postulated to work as a tumor-suppressor gene. However, it has been difficult to determine allele loss in cHL cases because CGH analysis is laborious and requires large numbers of microdissected cells [12]. FICTION was used in the present study to overcome this limitation.

In the 25 cases thought to have no TNFAIP3 loss, sequence data were available for 14 of which three showed TNFAIP3 mutations and the chromatogram did not show the remaining wild-type allele. This result is compatible with that of previous allele-specific CGH analysis, which showed a significant number of B-cell lymphoma cases with uniparental disomy (UPD) [3]. Of the three cases with TNFAIP3 mutations in the present study, loss of function was caused by UPD. However, for the remaining 11 cases in which both FICTION and sequence data were available, no TNFAIP3 deletion was again noted.

We found that B symptoms were more frequent in cases with TNFAIP3 deletions, although the difference was not statistically significant. Knockout experiments have suggested that TNFAIP3 plays a role in the termination of inflammation [13]. As B symptoms represent the inflammatory process, we speculated that absence of TNFAIP3 causes termination of the inflammatory process to fail, resulting in continuous activation of NF$\mathrm{\kappa B}$ signaling and classical Pel-Ebstein fever in $\mathrm{cHL}$ patients. However, to confirm this, further expression studies of the TNFAIP3 gene product in more cases are required.

All five cases with TNFAIP3 homozygous deletions in the present study were EBV-negative, as were four of the 14 cases of heterozygous deletion. Schmitz et al. previously found that the frequency of TNFAIP3 mutations in EBVnegative cases was significantly higher than in EBV-positive cases [7]. As our study included fewer EBV-positive cases, we could not confirm this report and further study including methylation analysis of TNFAIP3 will be necessary.

\section{Conclusion}

Homozygous deletion of TNFAIP3 in cHL cases might be more frequent than previously thought. Homozygous deletions were found in $11 \%$ of our cases, and our findings strongly suggest that TNFAIP3 serves as a tumorsuppressor gene in cHL. Screening for TNFAIP3 by FICTION analysis is a useful, cost-effective and rapid research tool to identify heterogeneity among $\mathrm{cHL}$ cases.

\section{Abbreviations}

CHL: Classical Hodgkin lymphoma; CGH: Comparative genomic hybridization; FICTION: Fluorescence immunophenotyping and interphase cytogenetics as a tool for the investigation of neoplasm; FISH: Fluorescence in situ hybridization; HL: Hodgkin lymphoma; HR-S: Hodgkin Reed-Sternberg; LD: Lymphocyte-depletion; LR: Lymphocyte-rich; MC: Mixed cellularity; NS: Nodular sclerosis; UPD: Uniparental disomy.

\section{Competing interests}

The authors declare that they have no competing interests.

\section{Authors' contributions}

$\mathrm{JN}, \mathrm{AMD}$, and HT performed the FICTION analysis. JN, NH, MK, KTa, MS, and HN carried out microdissection experiments. JN, MK, MS, KTa, and YK performed mutation analysis of TNFAIP3. FH prepared the FICTION probe. KTa, YA, WM, NS, DM, TW, YK, and KTo prepared tumor specimens. JN, SO and $\mathrm{YK}$ participated in study design, and $\mathrm{YK}$ and JN wrote the manuscript. All authors discussed the results and commented on the manuscript.

\section{Acknowledgements}

This work was supported in part by a Grant-in-Aid for Cancer Research from the Ministry of Health, Labour and Welfare of Japan (Clinical Cancer Research 22-014, 22-031, and 23-014) and the National Cancer Center Research and Development Fund (21-6-3, 20-1, 23-A-23, and 23-C-7). We are grateful to Dr. Tetsuo Kubota at Tokyo Medical and Dental University for advice in preparing the manuscript.

\section{Author details}

${ }^{1}$ Hematology Division, National Cancer Center Hospital, Tokyo, Japan. ${ }^{2}$ Section of Microbiology and Immunology, Tokyo Medical and Dental University Graduate School of Health Care Sciences, Tokyo, Japan. ${ }^{3}$ Cancer Genomics, Faculty of Medicine, The University of Tokyo, Tokyo, Japan. ${ }^{4}$ Pathology Division, National Cancer Center Hospital, Tokyo, Japan. ${ }^{5}$ Cancer Genomics Division, National Cancer Center Research Institute, Tokyo, Japan. ${ }^{6}$ Early Carcinogenetic Division, Research Institute, National Cancer Center Hospital, Tokyo, Japan. ${ }^{7}$ Pathology Project for Molecular Targets, The Cancer Institute, Japanese Foundation for Cancer Research, Tokyo, Japan.

Received: 30 May 2012 Accepted: 2 October 2012

Published: 5 October 2012

\section{References}

1. Vereecke $L$, Beyaert $R$, van Loo G: The ubiquitin-editing enzyme $A 20$ (TNFAIP3) is a central regulator of immunopathology. Trends Immunol 2009, 30:383-391. 
2. Malynn BA, Ma A: A20 takes on tumors: tumor suppression by an ubiquitin-editing enzyme. J Exp Med 2009, 206:977-980.

3. Kato M, Sanada M, Kato I, Sato Y, Takita J, Takeuchi K, Niwa A, Chen Y, Nakazaki K, Nomoto J, Asakura Y, Muto S, Tamura A, lio M, Akatsuka Y, Hayashi Y, Mori H, Igarashi T, Kurokawa M, Chiba S, Mori S, Ishikawa Y, Okamoto K, Tobinai K, Nakagama H, Nakahata T, Yoshino T, Kobayashi Y, Ogawa S: Frequent inactivation of A20 in B-cell lymphomas. Nature 2009, 459:712-716.

4. Compagno M, Lim WK, Grunn A, Nandula SV, Brahmachary M, Shen Q, Bertoni F, Ponzoni M, Scandurra M, Califano A, Bhagat G, Chadburn A, Dalla-Favera R, Pasqualucci L: Mutations of multiple genes cause deregulation of NF-kappaB in diffuse large B-cell lymphoma. Nature 2009, 459:717-721.

5. Honma K, Tsuzuki S, Nakagawa M, Tagawa H, Nakamura S, Morishima Y, Seto M: TNFAIP3/A20 functions as a novel tumor suppressor gene in several subtypes of non-Hodgkin lymphomas. Blood 2009, 114:2467-2475.

6. Novak U, Rinaldi A, Kwee I, Nandula SV, Rancoita PM, Compagno M, Cerri M, Rossi D, Murty W, Zucca E, Gaidano G, Dalla-Favera R, Pasqualucci L, Bhagat G, Bertoni F: The NF-KB negative regulator TNFAIP3 (A20) is inactivated by somatic mutations and genomic deletions in marginal zone lymphomas. Blood 2009, 113:4918-4921.

7. Schmitz R, Hansmann ML, Bohle V, Martin-Subero Jl, Hartmann S, Mechtersheimer G, Klapper W, Vater I, Giefing M, Gesk S, Stanelle J, Siebert R, Kuppers R: TNFAIP3 (A20) is a tumor suppressor gene in Hodgkin lymphoma and primary mediastinal B cell lymphoma. J Exp Med 2009, 206:981-989.

8. Chanudet E, Huang Y, Ichimura K, Dong G, Hamoudi RA, Radford J, Wotherspoon AC, Isaacson PG, Ferry J, Du MQ: A20 is targeted by promoter methylation, deletion and inactivating mutation in MALT lymphoma. Leukemia 2009, 24:483-487.

9. Schumacher MA, Schmitz R, Brune V, Tiacci E, Doring C, Hansmann ML, Siebert R, Kuppers R: Mutations in the genes coding for the NF-kappaB regulating factors IkappaBalpha and $\mathrm{A} 20$ are uncommon in nodular lymphocyte-predominant Hodgkin's lymphoma. Haematologica 2010, 95:153-157.

10. Korac $P$, Jones $M$, Dominis $M$, Kusec $R$, Mason DY, Banham AH, Ventura RA: Application of the FICTION technique for the simultaneous detection of immunophenotype and chromosomal abnormalities in routinely fixed, paraffin wax embedded bone marrow trephines. J Clin Pathol 2005, 58:1336-1338.

11. Cabanillas F, Pathak S, Trujillo J, Grant G, Cork A, Hagemeister FB, Velasquez WS, McLaughlin P, Redman J, Katz R: Cytogenetic features of Hodgkin's disease suggest possible origin from a lymphocyte. Blood 1988, 71:1615-1617.

12. Hartmann S, Martin-Subero JI, Gesk S, Husken J, Giefing M, Nagel I, Riemke J, Chott A, Klapper W, Parrens M, Merlio JP, Kuppers R, Brauninger A, Siebert R, Hansmann ML: Detection of genomic imbalances in microdissected Hodgkin and Reed-Sternberg cells of classical Hodgkin's lymphoma by array-based comparative genomic hybridization. Haematologica 2008, 93:1318-1326.

13. Lee EG, Boone DL, Chai S, Libby SL, Chien M, Lodolce JP, Ma A: Failure to regulate TNF-induced NF-kappaB and cell death responses in A20-deficient mice. Science 2000, 289:2350-2354.

doi:10.1186/1471-2407-12-457

Cite this article as: Nomoto et al:: Deletion of the TNFAIP3/A20 gene detected by FICTION analysis in classical Hodgkin lymphoma. BMC Cancer 2012 12:457.

\section{Submit your next manuscript to BioMed Central and take full advantage of:}

- Convenient online submission

- Thorough peer review

- No space constraints or color figure charges

- Immediate publication on acceptance

- Inclusion in PubMed, CAS, Scopus and Google Scholar

- Research which is freely available for redistribution 